\title{
Estrutura ou dispositivo: como (re)pensar a diferença sexual hoje?
}

\author{
Mariana Ferreira Pombo' (iD 0000-0002-6896-6691 \\ 'Universidade Federal do Rio de Janeiro, Programa de Pós-Graduação em Teoria \\ Psicanalítica, Rio de Janeiro, RJ, Brasil. 22290-240 - teoriapsi@gmail.com
}

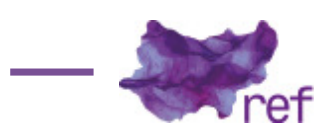

Resumo: Este artigo pretende problematizar e repensar o conceito de diferença sexual na contemporaneidade, considerando as transformações no campo da sexualidade e da família que interrogam a ahistoricidade e a imutabilidade dessa categoria. Na primeira parte do artigo será exposta a interpretação estruturalista da diferença sexual, a partir da teoria de Françoise Héritier, e uma leitura (negativa) da cultura feita por Michel Schneider baseada na diferença sexual como estrutura. Na segunda parte, será feito um trabalho de desconstrução da categoria de diferença sexual, pensada como dispositivo, e não como estrutura. Ideias de Joel Birman, Judith Butler, Sabine Prokhoris e Deleuze e Guattari serão apresentadas com o objetivo de romper com uma ontologia da diferença sexual e positivar múltiplas diferenças.

Palavras-chove: diferença sexual; contemporaneidade; estrutura; dispositivo; diferenças

Structure or Apparatus: How To (Re)Think Sexual Difference Nowadays?

Abstract: This article aims to examine and rethink the concept of sexual difference in the contemporaneity, considering the changes in the fields of sexuality and family, which interrogate the ahistoricity and the immutability of this category. In the first part, the article brings the structuralist interpretation of sexual difference, from Françoise Héritier's theory, and a (negative) lecture of the culture by Michel Schneider based on the sexual difference as structure. In the second part, a work of deconstruction of the category of sexual difference, taken as apparatus, not as structure, will be carried out. Ideas from Joel Birman, Judith Butler, Sabine Prokhoris and Deleuze and Guattari will be presented, aiming at breaking with sexual difference's ontology and valorising multiple differences.

Keywords: Sexual Difference; Contemporaneity; Structure; Apparatus; Differences

\section{Introdução}

No começo da década de 80, a filósofa e psicanalista Luce Irigaray (1984), em seu livro "Éthique de la différence sexuelle", afirma, partindo da ideia de Heidegger de que cada época tem uma, e apenas uma, questão a ser pensada, que provavelmente a questão do nosso tempo é a diferença sexual.

Hoje, três décadas após essa afirmação de Irigaray, a importância e a urgência de se debruçar sobre a questão da diferença sexual parece ter aumentado ainda mais. No campo da sexualidade e da família, transformações significativas se dão. Se o movimento feminista já vem desde os anos 70 e 80 obtendo conquistas significativas no sentido da separação entre sexualidade e reprodução, e entre erotismo e maternidade (a invenção da pílula anticoncepcional, a despenalização do aborto, o acesso à procriação medicamente assistida), na década de 90 a revolução se acentua e complexifica, a partir dos debates centrados nas formas de reconhecimento da união de casais homossexuais e no seu acesso à filiação, e nas demandas de mudança de sexo feitas pelos transexuais.

Desse modo, na contemporaneidade surgem novos corpos, práticas sexuais, identidades de gênero, arranjos familiares, tecnologias, leis, que interrogam o modelo binário e hierárquico de diferença sexual que há mais de duzentos anos predomina em nosso imaginário social. 
Neste contexto, este artigo pretende justamente problematizar o conceito de diferença sexual na contemporaneidade. Parte-se aqui de dois elementos. Em primeiro lugar, do incômodo em relação a autores, sobretudo da sociologia e da psicanálise, que se apoiam em uma interpretação estruturalista, ahistórica, da diferença sexual e, a partir dela, produzem apenas diagnósticos negativos e patológicos de nossa cultura. O jargão que se repete, como veremos mais detalhadamente a seguir, é o do risco de "apagamento" ou "abolição" da diferença sexual necessária à subjetivação.

Em segundo lugar, da aposta de que outra intepretação da diferença sexual é possível - a histórica, que entende a diferença sexual não como estrutura, mas como dispositivo, no sentido foucaultiano do termo. Dessa primeira aposta deriva uma segunda, a de que pode haver outros dispositivos discursivos, outros códigos e linguagens para diferenciação dos indivíduos e para repensar as subjetividades e sexualidades na atualidade de modo positivo e acolhedor.

O artigo se iniciará com a exposição da teoria da socióloga estruturalista Françoise Héritier, sucessora de Lévi-Strauss, que estabelece a diferença sexual como fundante de nossa cultura. Depois veremos como o psicanalista Michel Schneider resgata e sustenta, mesmo que nem sempre de forma explícita, uma ontologia da diferença sexual tal como proposta por Héritier, para criticar na contemporaneidade o que chama de apagamento da diferença sexual.

Em seguida, o artigo analisará propostas de autores inspirados por Michel Foucault e por sua ideia de raridade discursiva (Michel FOUCAULT, 1969, 1979), que, ao propor que o que é poderia ser diferente, indica a imaginação de possibilidades e a necessidade de investigação histórica. Trata-se, assim, de delinear a possibilidade da interpretação histórica da diferença sexual, como dispositivo (e não como estrutura). Começaremos com a genealogia do paradigma moderno da diferença sexual traçada por Joel Birman, e depois exploraremos novos dispositivos de definição e acolhimento das subjetividades e sexualidades propostos por Judith Butler, Sabine Prokhoris, e Deleuze e Guattari.

\section{Diferença sexual como estrutura}

A socióloga Françoise Héritier é muito citada nas discussões contemporâneas sobre diferença sexual, mais especificamente seu argumento, defendido nos dois volumes de seu livro "Masculin/ Féminin" (respectivamente "La pensée de la différence", de 1996, e "Dissoudre la hiérarchie", de 2002): o de que a diferença dos sexos está no fundamento de todo pensamento e, consequentemente, da cultura (ou da "ordem simbólica", expressão muito usada hoje).

É da observação da diferença entre os sexos que decorre, segundo a autora, a oposição conceitual essencial entre o idêntico e o diferente, que por sua vez está na base dos sistemas que regulam nosso universo mental e que opõem, dois a dois, noções abstratas ou concretas, como quente e frio.

Essa categorização dualista de base é a meu ver oriunda da observação liminar da diferença sexuada sobre a qual a vontade humana não tem domínio. Ela está no centro de todos os sistemas de pensamento em todas as sociedades. Todos funcionam de fato com categorias dualistas, oposições binárias de caráter concreto ou abstrato, as quais se acham, sobretudo as concretas, conotadas do signo do masculino e do feminino. (...) Nós pensaríamos de maneira diferente se não fôssemos sexuados e submetidos a essa forma particular de reprodução que é a procriação. A apreensão intelectual da diferença sexuada seria assim concomitante à expressão mesma de todo pensamento. (Françoise HÉRITIER, 2002, p. 15-16, tradução minha)

Em outras palavras, a observação primeira da diferença irredutível dos sexos, uma diferença biológica (uns têm pênis e outros, vagina) e de funcionamento fisiológico determina nossas categorias cognitivas binárias, como as operações de classificação, oposição, hierarquização, nas quais o masculino e o feminino se encontram presentes. Não há sistema de pensamento nem sistema social que não tenham sido fundados a partir do que a natureza oferece ao olhar. Em suas próprias palavras: "os sexos anatômica e psicologicamente diferentes são um dado natural; de sua observação decorrem noções abstratas cujo protótipo é a oposição idêntico/diferente, sobre a qual se moldam as tantas outras oposições conceituais de que nos servimos em nossos discursos de todas as ordens" (HÉRITIER, 1996, p. 26, tradução minha). Essas categorias cognitivas são extremamente duráveis, pois são inculcadas nos indivíduos desde muito cedo em seu ambiente cultural.

A diferença sexual é então, segundo ela, um dado biológico universal, imutável. Já a valência diferencial dos sexos, conceito criado pela autora, é uma tradução desse dado biológico, um artefato, que exprime uma relação hierárquica entre o masculino e o feminino, traduzível em termos de importância, valor, temporalidade (o que é anterior e o que é posterior). Embora o modo como essa valência diferencial dos sexos se traduz nas instituições e grupos sociais varie, há sempre o domínio do princípio do masculino sobre o do feminino, valorização do primeiro em detrimento do segundo.

Em todas as sociedades, a diferença entre os sexos é traduzida em uma linguagem binária e hierárquica. A valência diferencial dos sexos traduz o lugar diferente que é atribuído 
universalmente aos dois sexos. "Essas categorias são hierarquizadas e não de natureza igualitária: o masculino é superior ao feminino, como o calor ao frio, a razão à selvageria, o construído ao incoerente" (HÉRITIER, 2002, p. 77, tradução minha). O que justifica "razão" ser superior em valor a "selvageria" ou "exterior" a "doméstico", por exemplo, é o fato de "razão" e "exterior" estarem associados ao signo masculino, enquanto "selvageria" e "doméstico" estão ligados ao feminino. Estes termos inclusive mudam de valor se em determinada cultura essa associação se inverter.

Héritier (1996, 2002) defende que, apesar de a valência diferencial dos sexos não ser natural como a diferença sexual em si, ela também se apresenta nas sociedades como um mecanismo invariante. Ou seja, a autora apresenta o binarismo e a hierarquia dos sexos como categorias universais. A valência diferencial dos sexos seria mesmo um dos pilares fundadores da família e da sociedade, ao lado dos três já propostos por Lévi-Strauss (1947) em "Les structures élémentaires de la parenté": a proibição do incesto, a divisão sexual das tarefas e uma forma reconhecida de união sexual.

Como quarto pilar nessa estrutura, indispensável para explicar o funcionamento dos outros três, que não dão conta da relação entre o masculino e o feminino, a valência diferencial dos sexos seria, portanto, necessária à construção da sociedade e de suas regras de funcionamento. A sociedade não poderia se construir de outra forma que não sobre esse conjunto de pilares interligados.

Héritier (2002) defende ainda que a valência diferencial dos sexos e a dominação masculina que a acompanha são a expressão de uma vontade dos homens de controlar a fecundidade das mulheres, o "poder" especificamente feminino de fazer crianças dos dois sexos, ou seja, reproduzir a sua forma e também a forma diferente da sua. Assim, um sistema simbólico foi colocado em prática para subverter e domesticar essa função, e para permitir a continuação da vida em sociedade. Pela inversão conceitual que marca a valência diferencial dos sexos, os homens ganham papel decisivo na procriação, o papel de domínio mesmo. Esse processo é chamado pela autora de "despossessão" das mulheres, porque elas se configuram apenas como um meio, simples material da procriação, controlada pela vontade masculina.

Diante dessa constatação, ela afirma, no primeiro dos dois volumes de "Masculin/féminin", que seria muito difícil se alcançar no futuro uma relação de igualdade entre homens e mulheres. A valência diferencial dos sexos, enquanto um pilar da sociedade, não poderia ser transformada. No segundo volume, porém, a socióloga parece rever essa impossibilidade de mudança, ao defender que, se a fecundidade é o lugar central da dominação do masculino, um modo possível das mulheres saírem dele é por meio do controle da fecundidade, tornado possível com o acesso à contracepção.

É importante esclarecer aqui que Héritier (2002) diferencia a igualdade de direitos e de representações sociais à qual a contracepção poderia levar as mulheres em relação aos homens de uma indiferenciação entre os sexos, que ameaçaria a construção da identidade sexual.

Querer chegar à indiferenciação entre os sexos é não levar em conta um dado com o qual o vivo deve compor, a saber a existência da diferença sexuada. (...) Ora, a luta contemporânea para que as mulheres acedam à liberdade e à dignidade de pessoa (...) tem por objeto um reequilíbrio político, intelectual e simbólico das categorias que formam o social para atingir uma situação mais justa e mais coerente com nossos saberes, e não uma inversão que reproduziria um sistema de desigualdade. (HÉRITIER, 2002, p. 207, tradução minha)

A ideia da autora então é a de que a contracepção pode permitir às mulheres acederem a uma igualdade em relação aos homens, mas no seio de uma diferença sexuada, reconhecida, aceita. Ou seja, a diferença dos sexos, real, visível, assim como a oposição entre idêntico e diferente oriunda dela são dados fundamentais, dos quais não se pode esquivar. O binarismo é intransponível. A diferença sexual poderia apenas ser percebida de modo não hierarquizado e assim dar origem a novos sistemas classificatórios onde a noção de feminino tenha valor igual a de masculino.

Na citação acima, Françoise Héritier estabelece uma diferença entre, por um lado, a luta das mulheres por igualdade de direitos nos âmbitos político e intelectual, e, por outro, o desejo de se chegar à indiferenciação entre os sexos, problemático porque colocaria em xeque " $A$ " diferença estruturante do humano e da cultura. Como veremos a seguir, o psicanalista Michel Schneider parece equivaler os dois termos da equação: o aumento recente da reivindicação feminista por igualdade de direitos entre homens e mulheres estaria contribuindo para o apagamento das diferenças entre os sexos e, consequentemente, para minar a ordem simbólica.

\section{Confusão dos sexos?}

Em seu livro "La confusion des sexes", Schneider (2007) defende o argumento, comum a outros sociólogos e psicanalistas, como Irène Théry (1997), Jean-Pierre Lebrun (1997, 201 1) e Charles Melman (2010) de que presenciamos na contemporaneidade o apagamento da diferença sexual. 
A singularidade de sua tese é a de que esse apagamento da diferença sexual conduz à indiferença ao sexo, à perda do desejo sexual. O autor critica o posicionamento político de socialistas e feministas na França nas últimas duas décadas, que, na sua opinião, reforça e acelera a indistinção crescente entre os sexos. Os dois primeiros parágrafos do livro já revelam o argumento que está por vir:

Sociólogos e psicanalistas fazem a constatação dupla de um apagamento da diferença entre homens e mulheres, e de uma perda da atração pelo sexo nas gerações jovens. Mas nenhum laço é feito entre essas evoluções. A tese deste livro: a indiferença ao sexo é consequência da indiferença entre os sexos, e o socialismo moral e político é hoje o meio mais moderno para nos livrarmos da sexualidade. (Michel SCHNEIDER, 2007, p. 9, tradução minha)

"Socialismo moral e político" inclui, segundo o autor, aqueles que pensam o laço social e as questões da esfera privada como assuntos do Estado e que desejam acabar com a "luta entre os sexos". Embora ele se refira à direita e à esquerda, sua crítica recai sobretudo sobre o Partido Socialista e as leis aprovadas a partir do governo de Lionel Jospin (de 1997 a 2002), com participação importante de Ségolène Royal, então ministra. Vale ressaltar que esse livro foi publicado em 2007, ano justamente no qual Ségolène concorria às eleições presidenciais francesas - que acabou perdendo no segundo turno para Nicolas Sarkozy. Schneider critica contundentemente o programa de campanha da candidata, que chama de "programa do socialismo assexualista" ou "programa maternalista do não-sexo", assim como sua participação como deputada nos anos anteriores.

O psicanalista desenvolve sua crítica à contemporaneidade a partir da crítica a leis e projetos de lei qualificados por ele de socialistas, que produziriam uma confusão dos sexos nas representações políticas e sociais, conduzindo à abolição da sexualidade.

Antes de realizar a crítica a essas leis, Schneider explicita como entende a diferença sexual: "O que é a diferença dos sexos? Primeiramente um fato biológico e anatômico, um elemento do real. Não se escolhe o sexo, só há dois: se cai em um corpo de menino ou de menina" (SCHNEIDER, 2007, p. 10, tradução minha). Para ele, referindo-se a Lévi-Strauss e aproximando-se também de Héritier, os indivíduos são divididos em homens e mulheres, e não há grau zero da diferença sexual, que é a diferença das diferenças. As reivindicações de minorias negariam a diferença dos sexos e pretenderiam instaurar a confusão ou indiferença dos sexos.

O erro do "socialismo contemporâneo" seria então acreditar ser possível pensar os sexos fora desse lugar, natural, biológico, estruturante, onde eles se definem um em relação ao outro. Ao colocar em questão a diferença dos sexos, ele minaria a ordem simbólica que essa diferença funda. O declínio da diferença dos sexos viria acompanhado por uma dessimbolização generalizada.

Um primeiro conjunto de leis criticado pelo autor diz respeito a novas medidas penais contra crimes sexuais na França. Alguns comportamentos sexuais até então não considerados crimes passam a sê-lo, como a prostituição (punição dos clientes) e o estupro dentro do casamento (relações sexuais que o marido impõe à mulher, sem o seu consentimento) ou têm suas definições alargadas, como o abuso sexual em ambientes de trabalho, que passa a incluir, além das ordens e ameaças graves que a lei já previa, outras atitudes como comentários sexuais e proposições sexuais não desejadas. Além disso, passa-se a valorizar mais o relato da vítima que, do mesmo modo como na pedofilia, ganha presunção de verdade.

Retomando a afirmação de Philippe Muray de que "a inveja do pênis deu lugar à inveja do penal", o argumento de Schneider é o de que essas novas sanções repressivas pretendem interditar certos excessos da sexualidade genital adulta e limitar as formas autorizadas do desejo, sobretudo do desejo heterossexual masculino. "Uma inversão completa foi feita: o Código Napoleão punia as mulheres de vida inadequada ou adúlteras: a sexualidade inadequada estava do lado feminino. O atual Código penal sanciona como sexualidade inadequada a do homem, presumida violenta, patológica" (SCHNEIDER, 2007, p. 65, tradução minha).

Schneider tem posição veementemente contrária às leis que punem a prostituição e o abuso em ambientes de trabalho, leis consideradas por muitas feministas na França como avanços no sentido da proteção da mulher e de seu corpo. O autor defende, inclusive, apoiando-se na psicanálise, que o desejo sexual é sempre violento e pode ser unilateral e abusivo, e que o desejo da mulher em particular pode estar associado à fantasia de não-consentimento, tornando-se assim complicado e difícil definir o limiar do abuso. Assim, segundo ele, a consequência da criação de leis que "penalizam" o desejo sexual (masculino) é o seu apagamento.

Outra medida que, para o autor, apaga a diferença sexual e contribui para a dessimbolização das relações sociais é a feminização dos nomes de profissões, funções e títulos, proposta por lei com o objetivo de corrigir desigualdades gramaticais. Segundo ele, essa lei reflete os ideais sexuais de algumas feministas na atualidade, que correspondem a teorias sexuais infantis, tais como descritas por Freud. Vale lembrar que a primeira delas nega a diferença dos sexos, ao atribuir um pênis a todos os indivíduos, homens e mulheres. Hoje essa negação da 
diferença sexual teria o sentido inverso: atribuiria a todas as mulheres uma aversão ao pênis e recomendaria aos homens um comportamento amoroso feminino.

Sua crítica é a de que haveria na atualidade um duplo movimento de dessexualização das instituições (casamento, procriação) e de sexualização da linguagem. A feminização das palavras conduziria, na sua opinião, à maternização da sociedade, a um maternalismo dessexualizante. Mãe nesse contexto é definida por ele como quem, por não se aceitar como insuficiente e faltante, quer que o filho não deseje deixá-la e, em última instância, que o filho não seja sexuado, não deseje.

Apesar de Michel Schneider não citar explicitamente a socióloga Françoise Héritier em seu livro, fica evidente que ele compartilha de sua interpretação estruturalista da diferença sexual como "a diferença das diferenças", já que entende qualquer tentativa de subverter o binarismo e, principalmente, a hierarquia entre masculino e feminino, como um grande risco de apagamento dos mecanismos de diferenciação simbólica, diferenciação sem a qual não há cultura, subjetividade ou desejo possíveis.

Héritier (2002) afirmou no segundo volume de "Masculin/Féminin" que o binarismo sexual é impassível de mudança (tese da qual discordo), mas a hierarquia entre os sexos poderia, ao contrário, ser superada pela construção de uma nova valência diferencial dos sexos. Schneider, porém, não admite sequer essa possibilidade. A luta feminista contra os resquícios do patriarcado e da dominação masculina na cultura francesa, que questiona e combate a ontologia da diferença sexual e a hierarquia entre os sexos, não é reconhecida como legítima, mas signo ou ameaça de dessimbolização e indiferenciação. A sua análise aponta apenas o que considera problemático, sem aceitar como legítimas as novas questões e demandas que surgem.

\section{Diferença sexual como dispositivo}

Como já anunciado na introdução deste artigo, o incômodo em relação a esse tipo de discurso como o de Schneider é o de que, ao interpretar de modo estruturalista a diferença sexual, ele se posiciona diante do que surge de novo no campo da sexualidade e da família pelo viés do negativo e do declínio. O recurso à imutabilidade e à ahistoricidade da categoria atrapalha, e mesmo impede, a proposição de alternativas para lidar e acolher esse novo na cultura e na clínica.

E não são só as conquistas do movimento feminista que são criticadas. Entram na lista das "ameaças" as reivindicações pelo reconhecimento legal da união homossexual e da homoparentalidade, as demandas de mudança de sexo feitas pelos transexuais, as novas tecnologias reprodutivas. Tudo isso é visto como risco de indistinção entre os sexos e consequentemente um ataque à ordem simbólica indispensável à subjetivação. Nas narrativas psicanalíticas, esses elementos são tidos como grandes vilões do Édipo e da função paterna.

É preciso, portanto, problematizar o conceito de diferença sexual na contemporaneidade, porque determinados discursos tidos como verdadeiros, ao sustentarem uma interpretação estruturalista e ahistórica da diferença sexual, acabam por prescrever as boas condições de subjetivação e por estabelecer distinções entre formas normais e formas desviantes de subjetividade, sexualidade e família. Consequentemente, afetam o modo como os indivíduos são vistos e tratados na cultura.

Quais seriam então outros posicionamentos e discursos possíveis, para acolher e dar conta na atualidade da complexidade e diversidade das subjetividades e sexualidades, que estariam excluídas do campo de inteligibilidade se interpretadas pelo discurso que vimos até então?

Ocupar outra posição nesse debate implica em interpretar a diferença sexual como dispositivo, e não como estrutura. Dispositivo é empregado aqui no sentido proposto por Foucault (1976) em "História da Sexualidade 1 - A vontade de saber" para definir sexualidade:

A sexualidade é o nome que se pode dar a um dispositivo histórico: não à realidade subterrânea que se apreende com dificuldade, mas à grande rede da superfície em que a estimulação dos corpos, a intensificação dos prazeres, a incitação ao discurso, a formação dos conhecimentos, o reforço dos controles e das resistências, encadeiam-se uns aos outros, segundo algumas grandes estratégias de saber e de poder. (FOUCAULT, 1976/2013, p. 116-117)

Nesse texto, Foucault explica que a articulação entre subjetividade e sexualidade, assim como a colocação do sexo no regime do normal e do patológico, não são dadas, e sim produzidas na modernidade. A emergência de uma preocupação nova de cada indivíduo com seus desejos e práticas sexuais, assim como a constituição de uma série de saberes e discursos sobre o sexo não surgem por acaso, e sim nesse contexto histórico e enunciativo específico.

Por meio de sua metodologia genealógica e ao problematizar as relações entre saber e poder, o autor põe em dúvida as aparentes naturalidade e ahistoricidade do conceito de sexualidade, usado e difundido pelos discursos e as teorias, inclusive a psicanálise. A função da desconstrução é então questionar evidências, desnaturalizar, pensar que o que é poderia não ser. 
Trata-se aqui, portanto, de realizar esse mesmo trabalho de desconstrução histórica da categoria de diferença sexual, pensando inclusive qual efeito ela tem sobre as subjetividades ao se apresentar como "objeto natural" - expressão de Paul Veyne (2008) em "Foucault revoluciona a história".

Ratificando a tese de que a diferença sexual é um dispositivo histórico de poder, acompanharemos a seguir a genealogia do paradigma da diferença sexual descrita por Joel Birman (2001) em "Gramáticas do erotismo". Veremos que esse paradigma foi construído na modernidade, em substituição ao modelo antigo de sexo único, quando se passa a admitir a existência de dois sexos claramente distintos e separados um do outro. Observaremos que esse paradigma estabelece uma ontologia da diferença sexual, na medida em que o sexo, feminino ou masculino, é entendido como expressão inevitável de uma essência anatômica ou biológica. A constatação da contingência histórica do dispositivo diferença sexual nos permitirá prosseguir no artigo com a sua problematização e as tentativas de desconstrui-lo.

\section{Genealogia do paradigma da diferença sexual}

Joel Birman (2001) defende que o paradigma da diferença sexual é fundante e correlato da modernidade. Construído como um imperativo no imaginário cultural na virada do século XVIII ao XIX, ele substitui a concepção de sexo único, vigente desde a Antiguidade. Esse deslocamento do paradigma fundado no sexo único para o da diferença sexual, que entende que há dois sexos bem diferenciados um do outro, correspondeu a uma mudança de percepção e representação da diversidade sexual e teve efeitos importantes sobre as relações sociais entre os sexos.

O paradigma do sexo único, criado por Galeno e baseado na teoria das quatro causas de Aristóteles, pressupõe uma equivalência entre as genitálias masculina e feminina. Os sexos se diferenciam, então, de acordo com a presença ou a ausência do humor quente nos corpos. No homem, o humor quente está presente e determina a projeção da genitália no espaço exterior. Na mulher, ele está ausente, causando a invaginação da genitália no espaço interior do corpo.

Como o sexo é considerado único, há a possibilidade de transformação do feminino em masculino, se o humor quente se tornar predominante no corpo da mulher. Nesse processo, a invaginação da genitália feminina seria projetada para fora e a fêmea se tornaria macho. Porém, a transformação inversa, do masculino em feminino, não é possível. Essa impossibilidade está relacionada ao fato de o modelo masculino ser a representação do sexo perfeito, aproximado do divino. Já o feminino traz a marca da imperfeição, devido à ausência do humor quente. O perfeito não pode se transformar no imperfeito. O paradigma do sexo único, apesar da equivalência virtual das genitálias, é, portanto, hierárquico.

A homologia morfológica entre os sexos se inscreve em uma lógica marcadamente hierárquica, lógica que situa o masculino e o feminino em dois polos opostos, o primeiro representado pela luminosidade, a verdade, a atividade e a ação, e o segundo, pela obscuridade, a não verdade, a passividade e a recepção. Todas essas oposições estão associadas à oposição maior entre a exterioridade, projeção para fora, e a interioridade, invaginação, característica dos órgãos genitais.

O paradigma teórico do sexo único persistiu com força no imaginário ocidental desde a Antiguidade até o século XVIII. Ao longo desse século XVIII, com o imaginário e as exigências de igualdade de direitos formados pela Revolução Francesa, a hierarquia entre o homem e a mulher foi posta em questão. Foram criadas, assim, as condições de possibilidade para o declínio do modelo do sexo único e a construção de um novo modelo sexual, o discurso da diferença sexual.

A substituição do paradigma do sexo único pelo paradigma da diferença sexual não significou, porém, o fim da hierarquia entre os sexos. Ela foi apenas deslocada para o registro biológico da natureza e ganhou legitimidade do discurso da ciência. Seguindo a leitura naturalista da diversidade sexual que caracteriza a modernidade, os sexos passam a ser entendidos como possuindo essências radicalmente diferentes: "Enfim, a marca sexual que cada um portava, seja masculina ou feminina, passou para o nível da essência, constituindo-se, então, uma ontologia da diferença sexual" (Joel BIRMAN, 2001 , p. 43). Ser mulher ou homem se torna então a consequência inevitável de traços naturais, inscritos na estrutura do organismo.

A partir dessa ontologia da diferença sexual, o ser do homem e o ser da mulher, bem como as finalidades sociais e os horizontes possíveis para cada um deles, passam a ser definidos por marcas inscritas em suas configurações anatômicas e em suas regularidades fisiológicas. A biologia do século XIX define caracteres primários e secundários de cada sexo, tornando-os inconfundíveis em termos somáticos. Os avanços da medicina nos séculos XIX e XX contribuem para que a diferença sexual seja enunciada em diferentes registros da natureza e em diversos níveis de complexidade do organismo, como o hormonal e o cromossômico. Chega-se a um modelo sexual, portanto, no qual os sexos se discriminam de modo definitivo e irreversível, sendo impossível a transformação de um no outro.

A teoria da diferença sexual manteve a hierarquia e a relação de poder entre os sexos. Um 
conjunto de oposições sociais entre os sexos se legitimou na modernidade, baseado nas diferenças naturais entre eles e também nos desdobramentos diretos delas sobre as faculdades mentais. Assim, enquanto o homem era associado ao espaço público, ao registro dos direitos e da razão, a mulher o era ao espaço privado, à família, ao registro dos costumes e do sentimento. O homem estaria mais próximo do polo da civilização e a mulher, do polo da natureza e da maternidade.

O paradigma da diferença sexual prevalece ainda hoje em nosso imaginário social, há pelo menos duzentos anos, e de maneira bastante naturalizada. A própria teoria psicanalítica, desde Freud, passando por Lacan e chegando aos psicanalistas contemporâneos, se mostra atravessada por ele e com frequência o reforça. A afirmação freudiana de que a "a anatomia é o destino", por exemplo, está coadunada com o pressuposto de que as faculdades psíquicas são efeitos diretos de marcas biológicas. Corpos somáticos distintos ordenariam de modos também diferentes os psiquismos, do homem e da mulher.

Birman se propõe a desnaturalizar o paradigma moderno da diferença sexual, inscrevendoo na temporalidade histórica. Ou seja, mostra o caráter construído, histórico - de dispositivo, portanto - da categoria de diferença sexual, em oposição à sua interpretação estruturalista, que pressupõe a permanência do binarismo e da hierarquia como condição da cultura e da subjetivação.

\section{Questão em aberto}

Entender a diferença sexual (atrelada ao binarismo por um lado e à hierarquia entre o masculino e o feminino, por outro) como dispositivo significa que ela não existe enquanto um dado universal, estruturante do humano e da cultura. É, sim, uma construção histórica, uma entre outras tantas formas possíveis de entender e definir as subjetividades. A contrapartida dessa compreensão é aceitar que pode haver então outros dispositivos discursivos, outros códigos para (re)pensar os indivíduos e as sexualidades, aceitar que novas diferenciações são possíveis que não aquela binária, anatômica, hierárquica, que já se revela ultrapassada. $E$, é importante frisar, sem que isso seja um grande risco de indiferenciação ou de "confusão dos sexos".

Judith Butler (2012), em "Deshacer el género", critica explicitamente a tese ontológica da diferença sexual, a ideia vista aqui de que a diferença sexual é fundamental à cultura. A proposta da autora é a de que deixemos a diferença sexual como questão em aberto, a ser constantemente negociada, de modo que não tenha consequências naturais ou necessárias para a organização social da sexualidade: "Ao insistir em que esta será uma pergunta constante e aberta, quero sugerir que não tomemos nenhuma decisão sobre o que é a diferença sexual, que deixemos a questão aberta, que se converta em uma pergunta preocupante, sem resolver, propiciadora" (Judith BUTLER, 2012, p. 271, tradução minha). Fica evidente que a teoria butleriana se opõe à de Françoise Héritier: em vez de estrutura transcendental, a diferença sexual é para Butler uma categoria não fixa, aberta e que abre à reflexão.

Paola Marrati (2009), ao comentar a obra de Butler, resume que a tese da filósofa é a de que historicamente a diferença dos sexos funcionou, e continua hoje a funcionar, como o que torna a experiência possível, isto é, o que a torna inteligível e vivível. A prova desse papel histórico da categoria transcendente de diferença sexual são todos os indivíduos que, de modos diferentes e em lugares e épocas diferentes, foram e são excluídos do campo da experiência e da inteligibilidade aberto e regrado por ela.

Os próprios efeitos de exclusão, porém, colocam em questão o suposto status de estrutura transcendental da diferença sexual, porque se ela fosse realmente condição de possibilidade da experiência, não admitiria margens e exceções. Desse modo, Butler indica a historicidade do que se dá como estrutura e abre os limites do possível, os retira da influência de uma falsa necessidade.

Ela mostra não apenas que a diferença sexual não tem, nem de fato nem de direito, a inevitabilidade que se atribui a ela, mas também que essa diferença não está destinada a continuar nos limites de uma lógica binária. (...) O trabalho de Butler indica que uma diferença sexual não binária não tem nada de exótico, que é simplesmente um fato, um fato que concerne a todos, a cada um e cada uma de sua maneira sempre singular. (Paola MARRATI, 2009, p. 192, tradução minha)

A proposta de Butler, portanto, é a de que o marco da diferença sexual se mova além do binarismo e aceite a multiplicidade, já que a série de possibilidades do desejo e das experiências corporais e sexuais não se encontra dentro dos termos que existem para defini-las. Neste sentido, poderíamos dizer que não existem apenas o desejo masculino e o desejo feminino, como propõe Michel Schneider, mas múltiplos desejos. Nas palavras da autora: "Por que não deveria ser o caso que estivéssemos na borda da diferença sexual para a qual a linguagem da diferença sexual não é suficiente e que isto seja, de certa maneira, consequência de uma maneira de entender 0 corpo como constituído por múltiplas forças e constituinte de múltiplas forças?" (BUTLER, 2012, p. 280, tradução minha). 


\section{Vizinhança dos sexos}

Também a psicanalista Sabine Prokhoris (2000) entende a diferença sexual como dispositivo e procura valorizar o sexual como potência e intensidade que extrapolam os esquemas teóricos à nossa disposição. Em seu livro "Le sexe prescrit: la différence sexuelle en question", ela retoma a ideia foucaultiana de dispositivo de sexualidade para definir diferença sexual como efeito normativo, muito tenaz e concreto, de relações de poder concernindo o sexo e mantidas inquestionáveis.

Enquanto dispositivo de sexualidade, a diferença sexual faz parte do conjunto mais amplo de dispositivos reguladores de nossas maneiras de ser, pensar, amar, a que Prokhoris dá o nome de normas de existência ou "gramática da subjetivação". A partir do terceiro capítulo do livro, a autora passa a usar uma única palavra para se referir à diferença sexual, "diferençadossexos" ("différencedessexes", em francês), para mostrar a consistência do conceito e o fato de que é tido como princípio estruturante de tudo o que é humano.

O que Prokhoris defende, ao contrário, é que a diferença dos sexos não existe. Com isso ela quer dizer que, embora haja dois sexos anatômicos distintos, esse dado poderia ser pensado a partir de outra construção intelectual. A "diferençadossexos" constitui, portanto, uma solução de pensamento que foi preferida a outras para dar conta de um estado de coisas.

Pois a perspectiva que organiza a existência de cada sexo, o desenrolar de seus possíveis, e as figuras de suas relações, sob o ângulo exclusivo de uma diferença irredutível e por isso essencial, diferença que eles teriam em suma vocação para realizar - no duplo sentido dessa palavra , não é, entretanto, a única coerente que se possa conceber. Tanto que, se é com efeito na maior parte dos casos visível a olho nu que os meninos e as meninas não são exatamente idênticos, também é observável que, apesar dessa distância entre seus sexos respectivos, seus corpos e o que eles podem fazer deles se parecem enormemente. Se parecem e se diferenciam. A "diferençadossexos", ou seja, a representação que dispõe nesses termos, e segundo esse esquema, o fato tanto de sua proximidade como de sua dessemelhança, dando assim forma e sentido a uma situação com efeito surpreendente, não poderia ser simplesmente o produto de uma simples constatação - supondo que existe alguma coisa que se possa chamar constatação; supondo, dito de outro modo, que nossas percepções se contentam em placidamente registrar, depois retranscrever em representações "objetivas" uma realidade que não suscita nem a mínima perturbação nem a menor questão. (Sabine PROKHORIS, 2000, p. 122-123, tradução minha)

Nessa passagem podemos perceber que ela parte do princípio da raridade discursiva de Foucault: o fato de homens e mulheres terem órgãos genitais diferentes poderia ser interpretado de outro modo. A "diferençadossexos", embora pretenda ser a lei, é apenas uma representação, um esquema, dentre outros possíveis. Poderia haver outros dispositivos discursivos que definissem sob outra perspectiva a sexualidade dos indivíduos, o feminino e o masculino. E aí as condições de subjetivação, as suas formas "válidas", seriam outras.

No final desse trecho citado, observamos também uma crítica a Françoise Héritier, segundo a qual (como vimos) a diferença dos sexos está na base da criação da oposição fundamental que nos permite pensar. Ela seria o começo absoluto, a condição sine qua non do exercício do pensamento, pois pensar é classificar, classificar é discriminar e a discriminação fundamental está baseada na diferença irredutível dos sexos.

Em resposta ao pensamento de Héritier, Prokhoris afirma que a diferença dos sexos não poderia ser observada ou descoberta, como propõem antropólogos e psicanalistas, porque uma diferença não é uma coisa em si, mas uma maneira, entre outras possíveis, de interpretar, de tratar, de dar sentido e valor às distâncias e discordâncias entre as coisas observadas.

A proposta de Prokhoris então é a de que no lugar da diferença dos sexos coloquemos em funcionamento outro dispositivo de sexualidade, o da vizinhança dos sexos, que dissolve as linhas de divisão definitiva entre mulher e homem, e entende o sexual como potência intensiva, perversopolimorfa, fora de qualquer estruturação prévia pela "diferençadossexos". Recorrendo ao jogo da vizinhança, com o que ele comporta de deslizamentos e passagens, a autora argumenta que não existem nem o mesmo, nem o outro radical. Só há vizinhos, mais ou menos afastados um do outro.

\section{Máquinas desejantes e $\mathbf{n}$ sexos}

Em "O Anti-Édipo", Deleuze e Guattari (1973) também propõem o abandono do modelo binário transcendente de análise da diferença sexual. Trata-se de uma obra que critica o conceito de complexo de Édipo da psicanálise, sobretudo a sua pretensão de universalidade e a tentativa de enquadrar todo o desejo em um esquema explicativo, triangular, atrelado à família.

Os autores propõem o conceito de máquina desejante, um sistema de produzir desejos, como fluxos descodificados do desejo, vibrações. Para eles, o desejo é, portanto, da ordem da produção, é agenciamento maquínico. Não tem pessoas como objetos, mas meios inteiros que 
ele percorre, é sempre nômade e migrante. O desejo escapa, transborda quadros de referência, é revolucionário em si mesmo. Está em relação imediata com a realidade histórica e social.

Deleuze e Guattari valorizam, portanto, o múltiplo e o singular. No que diz respeito ao sexo e à diferença sexual, eles criticam o que denominam de "representação antropomórfica e molar do sexo", a ideia de que só há dois sexos estanques, não comunicantes. No fundamento dessa representação está, segundo eles, o conceito psicanalítico de castração como falta comum aos dois sexos, mas que se apresenta em cada um de uma maneira (inveja do pênis na mulher e medo de perdê-lo no homem).

No lugar de representação molar da sexualidade que culmina no que a funda, ou seja, a ideologia da falta, os autores apostam nas dimensões de multiplicidade pura e molecular que atravessam as máquinas desejantes. Eles propõem a existência, em cada indivíduo de n sexos, de um sexo "não humano", que se constitui a partir da circulação de intensidades e afetos impessoais e sem significação. Trata-se da dispersão de puras singularidades, multiplicidades livres em conexões, comunicações transversais, ou ainda de

uma transexualidade microscópica em toda parte, que faz com que a mulher contenha tantos homens quanto o homem, e o homem mulheres, capazes de entrar, uns com os outros, umas com as outras, em relações de produção de desejo que subvertem a ordem estatística dos sexos. Fazer amor não é fazer só um, nem mesmo dois, mas cem mil. Eis o que são as máquinas desejantes ou o sexo não humano: não um, nem mesmo dois, mas $n$ sexos. A esquizoanálise é a análise variável dos $n$ sexos num sujeito, para além da representação antropomórfica que a sociedade the impõe e que ele mesmo atribui à sua própria sexualidade. A fórmula esquizoanalíitica da revolução desejante será primeiramente esta: a cada um, seus sexos. (Gilles DELEUZE; Félix GUATTARI, 201 1, p. 390)

Assim, ao retirar o desejo do campo da representação e inseri-lo no domínio da produção e das diferenças múltiplas, Deleuze e Guattari também trazem uma proposta nova, não estruturalista, de diferenciação simbólica dos sujeitos. A sexualidade esquizoide, anedipiana, ultrapassa o dualismo sexual e possibilita uma abertura para o devir singular da vida de todos e de cada um (Carlos Augusto PEIXOTO JÚNIOR, 2010).

\section{Considerações finais}

A partir das ideias expostas de Joel Birman, Judith Butler, Sabine Prokhoris e Deleuze e Guattari, este artigo procurou problematizar e desconstruir a categoria de diferença sexual e seus pressupostos de ahistoricidade e de condição estruturante do humano e da cultura.

O trabalho de problematização e de desconstrução nos faz compreender que certas teorias e conceitos, ao classificar e hierarquizar indivíduos e suas práticas, atos e experiências, produzem subjetividade, seja por provocar angústia em relação ao possível desvio, seja por ditar a maneira como esses indivíduos são vistos e tratados pelo outro em uma dada cultura.

O que é fundamental de se compreender aqui é que sujeitos, experiências e práticas sempre poderiam ser interpretadas de outra maneira, a partir de outras teorias, fazendo-se uso de outros conceitos, e que isso mudaria completamente o modo de se olhar para eles e de tratá-los, assim como a maneira de os próprios indivíduos se pensarem.

(Re)pensar a diferença sexual como apenas um dispositivo dentre tantos outros possíveis para definir o humano e o sexual nos permite acolher sexualidades e subjetividades atuais, que seriam definidas como desviantes ou ininteligíveis por aqueles que ainda interpretam a diferença sexual como estrutura (imutável).

Butler fala de uma categoria não fixa, aberta à reflexão; Prokhoris, do dispositivo vizinhança dos sexos, em que o sexual é potência intensiva. Deleuze e Guattari, de máquinas desejantes e n sexos. Em comum, eles trazem novas apostas de diferenciação dos sujeitos e, com elas, a aceitação e a positivação das diferenças, rompendo com uma ontologia da diferença sexual.

Para concluir, é fundamental esclarecer que romper com uma ontologia da diferença sexual não significa chegar à indiferenciação ou à confusão. Muito pelo contrário, o trabalho de desconstrução possibilita que se chegue a uma multidão de diferenças, heterogeneidades, singularidades, a múltiplas modalidades de erotismo e de exercício da alteridade.

\section{Referências}

BIRMAN, Joel. Gramáticas do erotismo: a feminilidade e suas formas de subjetivação em psicanálise. Rio de janeiro: Civilização brasileira. 2001.

BUTLER, Judith. Deshacer el género. Barcelona: Paidós, 2012.

DELEUZE, Gilles; GUATTARI, Félix. O Anti-Édipo. São Paulo: Editora 34, 2011 [1973].

FOUCAULT, Michel. A arqueologia do saber. 7. ed. Rio de Janeiro: Forense Universitária, 2008 [1969]. 
FOUCAULT, Michel. História da sexualidade 1: a vontade de saber. 23. ed. Rio de Janeiro: Graal, 2013 [1976].

FOUCAULT, Michel. Microfísica do poder. 24. ed. Rio de Janeiro: Graal, 2007 [1979].

HÉRITIER, Françoise. Masculin/Féminin I: la pensée de la différence. Paris: Odile Jacob, 1996.

HÉRITIER, Françoise. Masculin/Féminin Il: dissoudre la hierárchie. Paris: Odile Jacob, 2002.

IRIGARAY, Luce. Éthique de la différence sexuelle. Paris: Les Éditions de Minuit, 1984.

LEBRUN, Jean-Pierre. Un monde sans limite. Toulouse: Érès, 1997.

LEBRUN, Jean-Pierre. Fonction maternelle, fonction paternelle. Bruxelles: Éditions Fabert, 2011.

LÉVI-STRAUSS, Claude. Les Structures Elémentaires de la Parenté. Berlin; New York: Monton de Gruyter, 2002 [1947].

MARRATI, Paola. "La vie et les normes". In: DAVID-MÉNARD, Monique (Org.). Sexualités, genres et mélancolie: s'entretenir avec Judith Butler. Paris: Campagne Première, 2009. p. 183-193.

MELMAN, Charles. La nouvelle économie psychique: la façon de penser et de jouir aujourd'hui. Toulouse: Érès, 2010.

PEIXOTO JÚNIOR, Carlos Augusto. "A multiplicidade sexual das máquinas desejantes e seus destinos". In: PRATA, Maria Regina (Org.). Sexualidades. Rio de Janeiro: Contra Capa, 2010. p. 27-46.

PROKHORIS, Sabine. Le sexe prescrit: la différence sexuelle en question. Paris: Flammarion, 2000.

SCHNEIDER, Michel. La confusion des sexes. Paris: Flammarion, 2007.

THÉRY, Irène. "Le contrat d'union sociale en question”. Esprit, Paris, v. 10, n. 236, p. 159-187, 1997.

VEYNE, Paul. "Foucault revoluciona a história". In: VEYNE, Paul. Como se escreve a história. 4. ed. Brasília: Editora UnB, 2008.

Mariana Ferreira Pombo (marifpombo@gmail.com) possui graduação em Psicologia (UFRJ, 2012) e em Comunicação Social (UFRJ, 2007), mestrado em Comunicação e Cultura (UFRJ, 2011 ) e doutorado em Teoria Psicanalítica (UFRJ, 2016), com período sanduíche na Université Paris Diderot (Paris 7). É psicanalista, membro do Espaço Brasileiro de Estudos Psicanalíticos, e atualmente bolsista de Pós-Doutorado nota 10 da FAPERJ, vinculada ao Programa de Pós-Graduação em Teoria Psicanalítica da UFRJ.

COMO CITAR ESSE ARTIEO DE ACORDO COM AS NORMAS DA REVISTA

POMBO, Mariana Ferreira. "Estrutura ou dispositivo: como (re)pensar a diferença sexual hoje?". Revista Estudos Feministas, Florianópolis, v. 27, n. 2, e54194, 2019.

\section{CONTRIBUIÇÃO DE AUTORIA}

Não se aplica

FINANCIAMENTO

FAPERJ (Bolsa de Pós-doutorado Nota 10)

CONSENTIMENTO DE USO DE IMAGEM

Não se aplica

APROVAÇÃO DE COMITÊ DE ÉTICA EM PESQUISA

Não se aplica 


\section{CONFLITO DE INTERESSES}

Não se aplica

LICENÇA DE USO

Este artigo está licenciado sob a Licença Creative Commons CC-BY Internacional. Com essa licença você pode compartilhar, adaptar, criar para qualquer fim, desde que atribua a autoria da obra.

\section{HISTÓRICO}

Recebido em 22/11/2017

Aprovado em 03/07/2018 